\title{
Recent Trends in Fly Ash Utilization in Polymer Composites
}

\section{S Anandhan}

Department of Metallurgical and Materials Engineering, National Institute of Technology, Karnataka, Mangalore-575025, India

*Corresponding author: S Anandhan, Department of Metallurgical and Materials Engineering, National Institute of Technology, Karnataka, Mangalore-575025, India, Tel: +91-824-2474000; E-mail: anandhan@nitk.edu.in

Received date: May 28, 2014; Accepted date: June 23, 2014; Published date: June 30, 2014

Copyright: (c) 2014 Anandhan S, et al. This is an open-access article distributed under the terms of the Creative Commons Attribution License, which permits unrestricted use, distribution, and reproduction in any medium, provided the original author and source are credited.

\section{Short Communication}

Fly ash (FA) is one of the residues created during the combustion of coal in coal-fired power plants. Fine particles rise with flue gases and are collected with filter bags or electrostatic precipitators. FA is a waste by-product material that must be disposed of or recycled. 131 million tons of FA is produced annually by 460 coal-fired power plants in the U.S. alone. Experts have predicted possible human health effects, like permanent respiratory disorder on inhalation of metals present in FA, especially by persons living in the vicinity of disposal sites [1]. Dumping of FA in to the environment causes pollution of air, land and water. FA is a waste ceramic that contains some heavy metal compounds and these could lead to a number of diseases, such as lung cancer, anemia, dermatitis and skin cancer. Since FA contains particulate matter $(\mathrm{PM})$ these can penetrate into different organs of the human system depending upon the size of PM [2].

Because FA is a by-product material, its chemical constituents can vary considerably, but, all types of FA include oxides of silicon, calcium, iron and aluminum. Depending on source, coal may include one or more toxic chemicals in trace amounts: arsenic, beryllium, boron, cadmium, chromium, cobalt, lead, manganese, mercury, molybdenum, selenium, strontium, thallium, and vanadium. ASTM C618 defines two classes of FA: Class C and Class F. ASTM C618 requirements: loss of ignition $<4 \%$ and $75 \%$ of ash must have fineness of $45 \mu \mathrm{m}$ or less. Primary difference between Class C and Class F fly ashes is the amount of calcium, silica, alumina, and iron content in the ash [3].

FA, when used as a cement replacement material, reduces greenhouse gas emissions. For every one ton of cement produced, about 6.5 million BTUs of energy are consumed. For every one ton of cement produced about one ton of carbon dioxide is released. Also, utilization of FA in various applications reduces volume of landfill space used for disposal of FA. The utilization of FA also has some disadvantages. There is a possibility of leaching toxic substances into soil, water, and atmosphere. It is proven by the U.S. environmental protection agency (EPA) that heavy metals have been leached from FA into ground water and underground aquifers in 39 locations in the U.S. The extent of leaching and hazardousness to humans of FA leachate is still unclear but the EPA is investigating it currently. Large ruptures of FA ponds, dams, or retention walls can cause catastrophic environmental damage to ecosystems and contaminate large areas with toxic substances.

FA has been used in a number of applications, ranging from mining to cement manufacturing. FA, when administered in a proper manner, can increase the yield of certain crops [4]. FA has been used in construction, as a low-cost adsorbent for the removal of organic compounds, flue gas and metals, light weight aggregate, mine back fill, road sub-base, and zeolite synthesis [5]. A considerable amount of research has been done using $\mathrm{FA}$ for adsorption of $\mathrm{NO}_{\mathrm{x}}, \mathrm{SO}_{\mathrm{x}}$, organic compounds, and mercury in air, dyes and other organic compounds in water. FA is a promising adsorbent for the removal of various pollutants. The adsorption capacity of FA may be increased after its chemical and physical activation. Also, FA has good potential for use in the construction industry.

The present utilization of ash on worldwide basis varies widely from a minimum of $3 \%$ to a maximum of $57 \%$, yet the world average only amounts to $16 \%$ of the total ash. Thermal power plants are the main sources for power generation in India as well as many other countries. There are about 40 major thermal power plants in India and they have been generating about two thirds of the country's power demands. India produces about 110 million tons of coal ash per year from burning about 300 million tons of coal per year for electric power generation. Nearly $73 \%$ of India's total installed power generation capacity is thermal, $90 \%$ of it is coal-based.

There is growing trend towards the development of composites with low environmental impact and good commercial viability. FA has been used in polymer matrix composites (PMC), saving the other commonly used mineral fillers in polymers, thereby reducing the greenhouse emissions. The main obstacle for utilizing FA in PMCs has been its surface polarity due to the presence of silanol, aluminol and other types of $-\mathrm{OH}$ groups attached to the metal/non-metal atoms of the constituents of FA. Many of the commercial polymers do not have substantial polarity that can match with that of the FA particles. This difficulty can be overcome by modifying the surface by suitable chemical reagents that are known as coupling agents. For example, one can choose from a variety of organosilanes or titanates.

FA has been used as reinforcement in polymer matrix composites widely and it was earlier used in various polymers, such as polyetheretherketone [6], polypropylene [7,8], epoxy [9], poly(vinyl alcohol) (PVA) [10], and high density polyethylene (HDPE) [11] and ethylene-octene copolymer (EOC) [12]. Alkadasi et al. [13] modified the surface of FA by a silane and the modified FA was used in making a PMC in which the matrix was polybutadiene rubber. Li et al. [14] developed and studied the properties of postconsumer poly (ethylene terephthalate)/FA composites. The densities and compressive strengths of the composites increased as a function of their FA content; the $\%$ shrinkage and water absorption decreased with increased FA loading. Sengupta et al. [7] prepared composites from recycled polypropylene and furfuryl palmitate-modified FA. Anandhan et al. [12] developed composites from EOC and unmodified as well as surfacemodified class-F FA (MFA) by twin screw extrusion. Addition of $20 \mathrm{wt} \%$ of MFA to EOC improved not only the tensile strength, but, also the stress values at $100 \%$ and $300 \%$ strains of the latter. Thermal stability of EOC matrix was appreciably improved by the addition of either FA or MFA. The 'flammable' 
nature of EOC changes to 'self-extinguishing' on addition of even 10\% of FA or MFA, as found out from limiting oxygen index study.

An innovative approach in value addition to FA has been introduced through the utilization of nano-structured FA (NFA) in PMCs by Paul et al., Satapathy et al. and Patil et al. [15-18]. Patil et al. [18] prepared NFA by high energy ball milling-induced mechanochemical activation aided by a surfactant. The modification considerably reduced the size of a single particle in nanometer range with rough surface and irregular shape. Also, the surface area of FA increased after ball milling. Subsequently, EOC/NFA composites were prepared by solution casting. NFA caused an improvement in mechanical properties and flame retardance of the composites even at the minimum filler loading. Particle-particle interaction forces in NFA are reduced by the use of a surfactant, which plays a significant role in enhancement of mechanical strength in NFA/PVA composite films obtained by solution casting. NFA improved the crystallinity and tensile strength of the bio-degradable PVA. Paul et al. [15] reported that styrene butadiene rubber (SBR)/NFA composites exhibited higher state of cure and higher strength properties as compared with carbon black-filled and fresh fly-ash-filled SBR composites at equivalent loadings. Satapathy et al. [16] studied the effect of electron beam irradiation on the technical properties of FA and NFA filled waste polyethylene. It was observed that the $\mathrm{FA} / \mathrm{NFA}$ at $5 \% \mathrm{w} / \mathrm{w}$ imparted enhanced technical properties. Satapathy et al. [17] found out that electron beam irradiation of HDPE/NFA composites enhanced their mechanical and dynamic mechanical properties.

Even though FA poses environmental pollution, it is an important raw material for various applications, such as civil construction, removal of organic compounds, heavy metals, dyes, and zeolite synthesis. For maximum benefit, new technologies for the efficient utilization of FA should be made use. Increasing FA utilization could reduce consumption of mineral resources, generate employment and add annual economic returns.

\section{References}

1. Dutta M (1997) Not So Inert After All! Fly Ash - an environment and health perspective.

2. Senapati MR (2011) Fly ash from thermal power plants - waste management and overview

Curr Sci 100: 1791-1794.
3. Mike Rafalowski (2011) Fly Ash Facts for Highway.

4. Parisara-Envis news letter (2007) Utility bonanza from dust 2: 6.

5. Ahmaruzzaman M (2010) A review on the utilization of fly ash. Prog Energy Combust Sci 36: 327-363.

6. Parvaiz MR, Mohanty S, Nayak SK, Mahanwar PA (2011) Effect of surface modification of fly ash on the mechanical, thermal, electrical and morphological properties of polyetheretherketone composites. Mater Sci Eng A 528: 4277-4286.

7. Sengupta S, Pal K, Ray D, Mukhopadhyay A (2011) Furfuryl palmitate coated fly ash used as filler in recycled polypropylene matrix composites. Compos B Eng 42: 1834-1839.

8. Satapathy BK, Das A, Patnaik A (2011) Ductile-to-brittle transition in cenosphere-filled polypropylene composites. J Mater Sci 46: 1963-1974.

9. Kulkarni SM, Kishore (2002) Effects of surface treatments and size of fly ash particles on the compressive properties of epoxy based particulate composites. J Mater Sci 37: 4321-4326.

10. Nath DCD, Bandyopadhyay S, Boughton P, Yu A, Blackburn D, et al. (2010) Chemically modified fly ash for fabricating super-strong biodegradable poly(vinyl alcohol) composite films. J Mater Sci 45: 2625-2632.

11. Deepthi MV, Sharma M, Sailaja RRN, Anantha P, Sampathkumaran P, (2010) Mechanical and thermal characteristics of high density polyethylene-fly ash Cenospheres composites. Mater Des 31: 2051-2060.

12. Anandhan S, Sundar SM, Senthil T, Mahendran AR, Shibulal GS, (2012) Extruded poly(ethylene-co-octene)-fly ash composites value added products from an environmental pollutant by S. Anandhan. J Polym Res 19: 9840 .

13. Alkadasi NAN, Hundiwale DG, Kapadi UR (2004) Effect of coupling agent on the mechanical properties of fly ash-filled polybutadiene rubber. J Appl Polym Sci 91:1322-1328.

14. Li Y, White DJ, Peyton RL (1998) Composite material from fly ash and post-consumer PET. Res Cons Recycl 24: 87-93.

15. Paul KT, Pabi SK, Chakraborty KK, Nando GB (2009) Nanostructured fly ash-styrene butadiene rubber hybrid nanocomposites. Polym Compos 30: $1647-1656$.

16. Satapathy S, Nag A, Nando GB (2011) Effect of electron beam irradiation on the mechanical, thermal, and dynamic mechanical properties of flyash and nanostructured fly ash waste polyethylene hybrid composites. Polym Compos 33: 109-119.

17. Satapathy S, Nando GB, Nag A, Raju KVSN (2013) HDPE-Fly Ash/Nano Fly Ash Composites. J App Polym Sci 130: 4558-4567.

18. Patil AG, Mahendran A, Anandhan S (2014) Nanostructured Fly Ash as Reinforcement in a Plastomer-Based Composite: A New Strategy in Value Addition to Thermal Power Station Fly Ash. Silicon. 